\title{
Circle Talk in Natural Approach to Improve Students' Participation in English Speaking
}

\author{
Aristo \\ Universitas Tanjungpura \\ aristone29@gmail.com \\ Sudarsono \\ Universitas Tanjungpura \\ sudarsono@fkip.untan.ac.id \\ Clarry Sada \\ Universitas Tanjungpura \\ clarry.sada@fkip.untan.ac.id
}

\begin{abstract}
This study is about improving students' participation in English speaking by applying Circle Talk in Natural Approach to Year - 8 of SMPN 7 Tayan Hilir. It involved 23 students. Students' participation stands for students' change of behavior related to the students' engagement and the total number of words delivered. The participation was observed by the researcher and the observer by using Oral Proficiency Scoring Categories supported by video recording. The use of Circle Talk in Natural Approach successfully improves the students' participation in English speaking. The mean score was 73, 21 in the first cycle and 74, 21 in the second cycle. Students' change of behavior in applying the strategy in the first cycle was 90, 66 and it was 94, 00 in the second cycle. Students' change of behavior which was notified from the Observation was compared from the Field Note written by the observer. Circle Talk in Natural Approach was found out helpful to improve students' participation in English speaking for Year -8 of SMPN 7 Tayan Hilir.
\end{abstract}

Keywords: Circle Talk, Natural Approach, Participation

\section{INTRODUCTION}

Basically, humans are born with a Language Acquisition Device (LAD) to enable them giving the mind in communication. To do so, in fact, the language argumentation devise does not allow the humans to easily find the help they need to deliver messages. To help them in communicating, humans need to participate to have interaction. In the process of communication, the ability of delivering messages has a close of relationship with how the humans do the interaction.

It is the same with the students' participation in English speaking in the year -8 of SMPN 7 Tayan Hilir. The year -8 students were not used to talking individual yet. They experienced that the classical teaching and learning process mostly force them to speak. In fact, the teaching learning process the English talk was mostly dominated by the teacher.

In such a condition, the teacher become a role model and actor in guiding and educating the students to have the interesting and the challenging teaching - learning process in order to enable them have high - valuable new learning experience. As Maley and Duff (2005) remarked: 'teachers are the key to the success of teaching learning process'. To do so, the researcher used Circle Talk in 
Natural Approach to improve students' participation in English speaking as the strategy and also the approach in teaching speaking. The use of Circle Talk in Natural Approach aims to overcome the gaps and the disproportion of learning by presenting the pleasant process of learning and creating the atmosphere which enable the students to think independently. Then, the research purposes of this study are formulated as follows: 1 . to identify the use of Circle Talk to improve students' participation in English speaking, 2. to identify the use of Circle Talk in Natural Approach in revealing skill and knowledge through students' learning experience, and 3. to classify the participation stands for.

A study by Winters (n.d.) talks about the use of Talking Circles in the classroom. The discussion of the study is about the basic purpose of the strategy which is used to create a safe, non-judgmental place where each participant has the opportunity to contribute to the discussion of difficult and/or important issues. In her research finding 'Talking Circles are more successful when the participants trust with each other because the trust builds relationship, explore values, and create guidelines for participation helps everyone feel physically, psychology, and emotionally safe in the circle and creates a foundation for courageous acts of sharing' (Winters, nd).

A study by Uba (2002) in English Specialization Course of Tuiuti University concludes the three main objectives of the research such as "student should be exposed to a comprehensible input", then the focus should be on meaning, and the acquisition should take place in a low anxiety'. In brief, the research paper definitely explains that the necessity of an interesting input and the need to take care over error-correction and meaningful communication, just to cite some and summarizes that the ultimate purpose of a foreign language course should be the provision of classes that encourage learning or acquisition rather than punishing failure.

Circle Talk is a strategy of teaching speaking. This teaching strategy engages and stimulates the students to be active learners, think independently and confidently in participating in English speaking activities. Besides, the teaching strategy is proposed as a strategy that requires students to participate naturally to speak in pair without having any force. The strategy which free from any force enables the students to do the strategy on the track. According to Maley and Duff (2005), 'for Circle Talk activities to work well, teachers themselves need to be convinced that they will work'. Through its forms, about eight students in each inner and each outer circle, the students are formed facing outward form the inner circle and students facing inward form the outer circle, so that each student from the inner circle has a partner in the outer circle. As a result, this activity enables the students to create any kind of structure of language as they focus on more the ideas, feeling and knowledge they share.

Natural Approach is a method of language teaching developed by Stefen Krashen and Tracy Terrell in the late of 1970 and early 1980s (Norland \& Said, 2006). In their view, 'Natural Approach is an approach or method which is used for emphasizing people to "acquire" languages best by learning naturally like children do' (Norland \& Said, 2006). The belief aims to create the language teaching become vivid, interesting, and challenging. To do so, the researcher used Natural Approach to achieve the effort that makes the learning environment as stress-free as possible to excite the learners naturally participate in English speaking.

In addition, such a condition facilitates the students to recognize the varieties of learning experience in achieving eagerness toward comprehensible input of knowledge on whole meaning of learning context. According to Norland and Said (2006), 'comprehension should precede production and that students should not be forced to speak until they are ready'. Consequently, the research implements Natural Approach as guidance for the researcher to present "naturalistic" to students' language learning process.

Students' Participation in English Speaking

Students' participation is the main objective of this research. The terms of students' participations in this research are the positive change of students' behavior related to the students' involvement and engagement in English speaking activities and also the total number of words which is delivered by the students in English - speaking presentation. Positive attitudes towards the target language culture may either stimulate learning, or may develop as a result of successful learning (Mishan, 2005). Then again, according to Prinsen, Terwel, Volman, and Fakkert (2008), 'active participation is measured in the number of messages that every student has contributed'. 


\section{METHOD}

Method of research deals with the method of research and procedures used. The design is classroom action research. This research was designed to improve students' participation in English speaking in expressing meaning through short and simple transactional and interpersonal dialogue to interact with the surrounding environment by using Circle Talk in Natural Approach. Creswell (2012) defines 'this type of research is used when a teacher has specific educational problem to solve.

The implementation of the research design applied in this research model was developed by Kemmis and Mc Taggart (1988). Kemmis and Mc Taggart as cited in Burns (1999, p. 35) outlines that there are four major steps in the action research process, such as Planning, Action, Observation and Reflection. Therefore, the researcher implemented the classroom action research into four steps to gather the information. This classroom action research conducted in two cycles.

From the survey, the researcher found that the students had difficulty for participating in English speaking activity. In brief, there were 20 of 21 (95\%) students felt that speaking in English is difficult. There were 20 of $21(95 \%)$ students did not like the activity of English speaking in the class. There were 19 of $21(90 \%)$ students were not interested with the activity of English speaking in the class. There were 19 of $21(90 \%)$ students felt worried as the teacher asked them to speak English. There were 19 of $21(90 \%)$ students did not feel really confident to speak English. There were 18 of 21 (86\%) students might feel more comfortable to speak English in pair or group. There were 20 of 21 $(95 \%)$ students felt that having friends in pair or group may enable them to get confidence. There were 18 of $21(86 \%)$ students felt that the teacher conducted the interesting English - teaching speaking. There were 9 of $21(43 \%)$ students thought that English speaking is the biggest problem they had. At last, there were 18 of $21(86 \%)$ students hoped that they have a proper teaching strategy that enables them to get involved in the activity English speaking.

The whole finding in from the survey showed that there were 9 of 21 (43\%) students to 20 of $21(95 \%)$ students thought that English speaking is the biggest problem they had. In addition, the researcher hypothesized that most students had low participation in English speaking. Therefore, to sum up, the mean finding of Preliminary Study the researcher concisely concluded that the students' low participation in English speaking was the basic problem in the class.

\section{Planning Phase}

Designing the strategy in which considered to promote the students to be more active, Circle Talk presents the students' participation in English speaking activity through interaction. Thornbury and Slade (2007) argue that in face-to-face interactions participants share not only the physical context (so that explicit mention of referents is often not necessary) but also the institutional, social and cultural contexts, as well. In their view, 'through face to face interactions the students do not have gabs to communicate in social contexts therefore the closed interactions enable the students to be free to communicate (2007, p. 15).

In brief, the teaching strategy forms the students to face others so that facilitates the students to have notice to each other. The teaching approach applied was also used to guide the students to have confidence and safety as the students did English speaking activities. Thus, for the Planning Phase, the researcher designed Circle Talk as the strategy and Natural Approach as the frame of the research. It purposed to reduce the anxiety and to present the effort that makes the learning environment as stress-free as possible.

Action Phase

In this step of the cycle, the teaching speaking transactional (to get things done) and interpersonal text and short functional text were divided into three main stages. They were Pre-Cycle (simulating), Task Cycle (mastering the questions connected with the topic) and Language Focus. Pre-Cycle (simulating) was conducted in the first meeting of Cycle 1. Task Cycle was conducted in the second meeting of Cycle 1, and then Language Focus was conducted in the third meeting of Cycle 1. In the second cycle, Pre-Cycle and Task Cycle were conducted in the first meeting of Cycle 2 and Language Focus was conducted in the second meeting of Cycle 2. The three main stages were observed by the observer by using Teacher's Observation Checklist Sheet. It aimed to observe the students' participation through the change of the students' behavior in applying the strategy. 
Table 1. Students' Participation in Applying the Strategy

Cycle 1

\section{Pre Task}

1. Students listened to teacher in introductory talk about asking and giving opinion.

2. Students participated in merging with friends to do the strategy.

3. Students showed curiosity with the activity they had.

4. Students listed their own opinion about famous artists and singers.

5. Students asked and gave based on the text given in pre activity.

\section{Task Cycle}

1. Students showed their enthusiasm in doing the strategy.

2. Students showed their independence in asking and giving opinion

3. Students helped each other in guiding friends and to ask and give information.

4. Students paid attention to listen to the instruction as they were doing the strategy.

5. In the implementation of the strategy, the students dared to speak as the spirit and framework of Natural Approach.

6. The students asked and shared opinion to their friends to implement of the strategy.

\section{Language Focus}

1. Students showed their enthusiasm in doing the class presentation.

2. Students showed their independence in delivering the information.

3. Students did the class presentation to share information.

4. Students listened to the instruction as they were doing the strategy.

5. In the implementation of delivering information through class presentation, the students dared to speak as the spirit and framework of Natural Approach.

6. The students shared to class about what they had in the post activity.

Table 2. Students' Participation in Applying the Strategy

Cycle 2

\section{Pre Task}

1. Students listened to teacher in introductory talk about asking and giving information in monologue text.

2. Students showed curiosity with the activity they had.

3. Students showed their enthusiasm in preparing themselves to do the strategy.

\section{Task Cycle}

4. Students participated in merging with friends to do the strategy.

5. The students asked and shared information in the implementation of the strategy.

6. Students helped each other in guiding friends and to ask and give information.

7. In the implementation of the strategy, the students dared to speak as the spirit and frame of Natural Approach.

8. Students showed their independence in asking and giving information.

9. Students asked and gave question and answer based on the monologue given.

10. Students listed their answer from friends they met.

\section{Language Focus}

1. Students paid attention to listen to the presentation from friends.

2. In the implementation of the strategy, the students dared to speak as the spirit and frame of Natural Approach.

3. Students showed their independence in delivering information.

4. Students showed their knowledge through the activity of class presentation.

5. Students have integrity in delivering the class presentation.

6. Students seemed enthusiasm in delivering their information.

7. Students showed their learner profile on the presentation 


\section{Observation Phase}

Students' participation in English speaking was observed through the way of how the students performed their attitude during the implementation of the strategy and also by counting the total number of words per message delivered by student individually in class presentation which was done by the observer and the researcher. It aimed to balance the findings so that the balance can give equal important findings. According to Burns, 'observation involves observing the outcomes of the intervention and reflecting on its effectiveness' (1999, p. 40).

Reflection Phase

For the purpose of research, the researcher and the collaborator recalled all the information from the instrument of data collection as the important feedback such as Teacher' Observation Checklist Sheet, Field Note, Scoring Rubric, and Questionnaire. Feedback is any information that is gathered and collated, by various methods and from different sources, and is only part of the attempt to establish the effectiveness of a course or program of study (Butcher, Davies, \& Highton, 2006, p. 188).

Through video recording, the researcher and the observer reviewed deeply about the process of English speaking activities. Then, both individually and collaboratively with the observer evaluated, reflected and gave input and critical comments. In this stage, the researcher and the observer decided the strength and also the weakness of the teaching strategy and also the teaching approach. According to Butcher, Davies, and Highton, 'reflection is time for both the observer and the observed to think about the event' (2006, p. 200).

Research Setting

The research was conducted at SMPN 7 Tayan Hilir District which is located on Jalan Trans Kalimantan, Kabupaten Sanggau. It was conducted in the second semester of academic year 2016/2017. The subject of this research was the students in year -8 of SMPN 7 Tayan Hilir. The total number of research subjects is 23 students. They consist of 10 male students and 13 female students. Butcher, Davies, and Highton (2006, p. 200) argue that "teacher" needs to consider two obvious questions: 'who will observe?' and 'which class?'

Techniques and Tools of Data Collection

The techniques of data collection applied in this research were supported by the existence of video recording. To do so, to support the researcher having the video recording; the researcher had a colleague from the same school who understands how to record the video recording for the whole activities of all cycles. According to Rees (2005), 'if the researcher chooses someone else to record, be sure the recorder understands the role and coach him or her along the way, if necessary'.

Then, to get the students' participation during the strategy applied, the researcher used Teacher's Observation Scoring Rubric. It aimed to see how the students achieve the indicators provided in each stage of the observation, such as students' change of behavior and eagerness as they participated and interacted in each meeting of the cycles. At last, the researcher distributed the questionnaire in end of Cycle 1 and Cycle 2 to see the students' responses toward the implementation of Circle Talk in Natural Approach.

To get the data collaboratively, both researcher and the observer investigated the video to view the whole work by using adapted Oral Proficiency Scoring Rubric made by Brown (2004). The criteria occurred are Task, Pronunciation, Fluency, Comprehension, Vocabulary, and Students' Participation (Total Number of Words per Message in English Speaking). The students' performance in class presentation of Cycle 1 and Cycle 2 was scored in the scale of 1 to 5 in each criteria. Based on the video recorded, both the researcher (rater 1) and the observer (rater 2) observed and scaled the students' performance based on the criteria achieved. Then, both researcher and also observer took a note and wrote down the words which were delivered by students. The focus of writing down the words was for counting and rating the total words per message as their participation in English speaking activity. Counting and rating the total number of words delivered individually was done to see the quantity of the students' participation in words delivered.

Techniques of Data Analysis

Techniques of data analysis were used to process the data therefore the data can be communicated well to others. According to Hatch (2002) 'data analysis is a systematic search for 
meaning. The triangulation technique of data analysis used to ensure the trustworthiness of the data. It aimed to maintain equilibrium of the research finding which was done by the researcher. Triangulation involves gathering data from a number of different sources so that the research findings can be tested out against each other (Burns, 1999). One of the techniques was by using the note from Field Note done by colleague. The existence of note (strengths and weaknesses) in Field Note noticed the researcher to keep upright the finding in Teacher's Observation. To ensure the trustworthiness of the data, the researcher (rater 1) and the observer (rater 2) collaboratively got involved to check and balance the process of measuring students' participation by using Oral Proficiency Scoring Categories.

To meet quality of the students' participation in English speaking, the researcher took the criteria of Task, Pronunciation, Fluency, Comprehension, and Vocabulary. Each criteria of the students' participation in English speaking was divided into 5 scales. Then, to meet the quantity of the students' participation in English speaking, the researcher took the criteria of Students' Participation (Total Number of Words per Message in English Speaking). It purposed to count and to rate the total number of words delivered by the students as they performed their class presentation individually. Each criteria of the students' participation (Total Number of Words per Message in English Speaking) was divided into 5 scales. The scale 1 was given to 1 to 20 words per message; the scale 2 was given to 21 to 40 words per message; the scale 3 was given to 41 to 60 words per message; the scale 4 was given to 61 to 80 words per message; and the scale 5 was given to 81 to 100 words per message. To sum up, the students' achievement in the quality of students' participation and the quantity of students' participation were converted with the total scale in Oral Proficiency Scoring Categories. The total scale in Oral Proficiency Scoring Categories is 30. The students' achievement in score was measured by dividing the total scale got by students then it multiplied by 100. The score which the students got was used as the research finding. Boyle and Fisher (2007) explain that effective test use depends not only upon careful selection of the instrument and practice in administration and scoring on the part of the test user, but also in ensuring that possible sources of bias and distraction in the testing environment are removed or at least minimized.

\section{RESULTS AND DISCUSSIONS}

Results

The data stated in this research was achieved from the implementation of classroom action research which covered the students' participation during the implementation of the communication through individual's speaking outcome and their responses toward their speaking ability through the use of Circle Talk in Natural Approach in Cycle 1 and Cycle 2.

Cycle 1

The data presented in this study were achieved from the implementation of classroom action research which covers the students' participation in applying the strategy in the first meeting, second meeting, and the third meeting, and students' participation within words in English speaking, students' score of participation in English speaking, and students' responses toward the implementation of Circle Talk through Natural Approach in English speaking.

Students' Participation in Applying the Strategy in Cycle 1

The percentage of the students' participation in applying the strategy in the first meeting was $92 \%$ and it was Very Good in the interpretation, $93 \%$ in the second meeting and it had very well in the interpretation, and $87 \%$ in the third meeting and it was Good in the interpretation. Then, the average percentage of students' participation in applying the strategy in Pre Task, Task Cycle, and Language Focus of Cycle 1 was $91 \%$ and it was Very Good in the interpretation. 


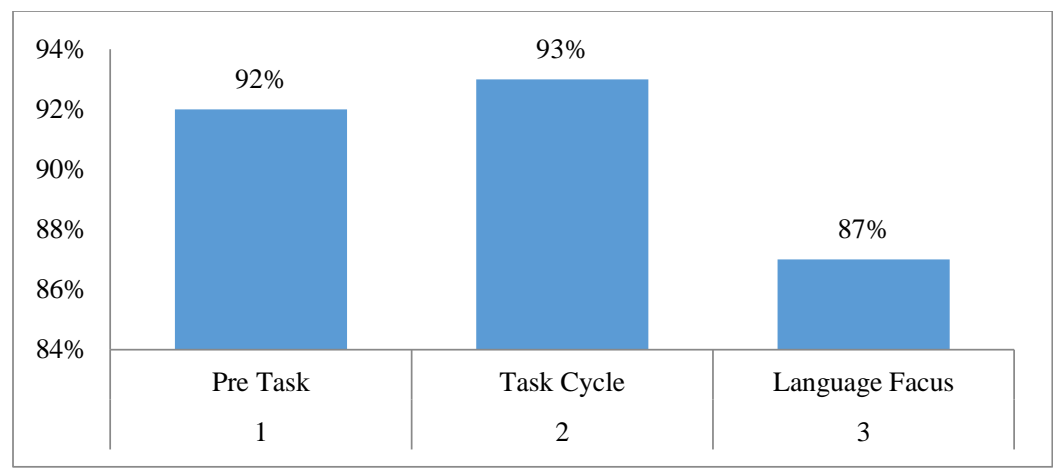

Fig. 1 Students' Participation in Applying the Strategy in Cycle 1

\section{Students' Participation within Words in English Speaking}

Based on the video recorded, both the researcher (rater 1) and the observer (rater 2) watched, observed the process then took a note and wrote down the words which were delivered by students. The focus of writing down the words was for counting and rating the total words per message as their participation in English speaking activity. The finding was used by the researcher to see the quantity of the students' participation in words delivered.

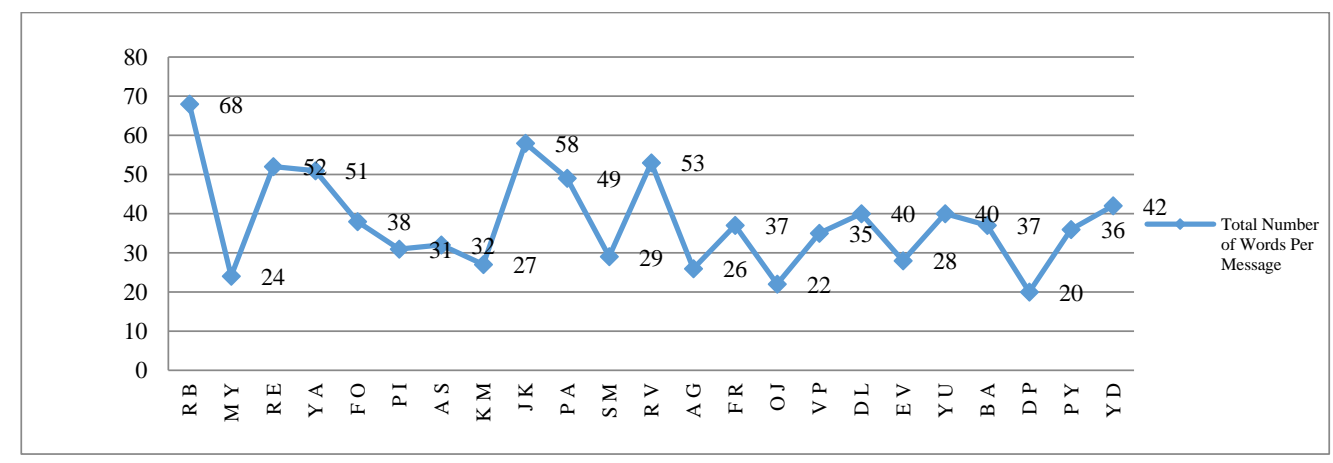

Fig. 2 Students' Participation within Words in Cycle 1

\section{Students' Score of Participation in English Speaking}

The students' final score was achieved from the scoring rubric. The scoring rubric used in measuring the finding was the integration of the total number of words per message delivered by the students which was scaled in 1 for ( 1 to 20 words), 2 for ( 21 to 40 words), 3 for (41 to 60 words), 4 for (61 to 80 words), and 5 for ( 81 to 100 words) and also the conversion of speaking rubric of five criteria in the frame of Natural Approach. The converted scoring rubric was adapted from the scoring rubric made by Brown (2004). They are Task, Pronunciation, Fluency, Comprehension, and Vocabulary. The scoring rubric was adapted by the researcher to meet the standardization objectives of the research finding in the frame of Natural Approach. The data then scored by using scoring rubric done by the two raters. The students' final score was the score achieved from rater 1 combined with the score got by rater 2 . Then, the combination of the score was divided by 2 to get the students' average score. The use of such a count was done to avoid subjectivity in scoring the students' speaking outcome. 


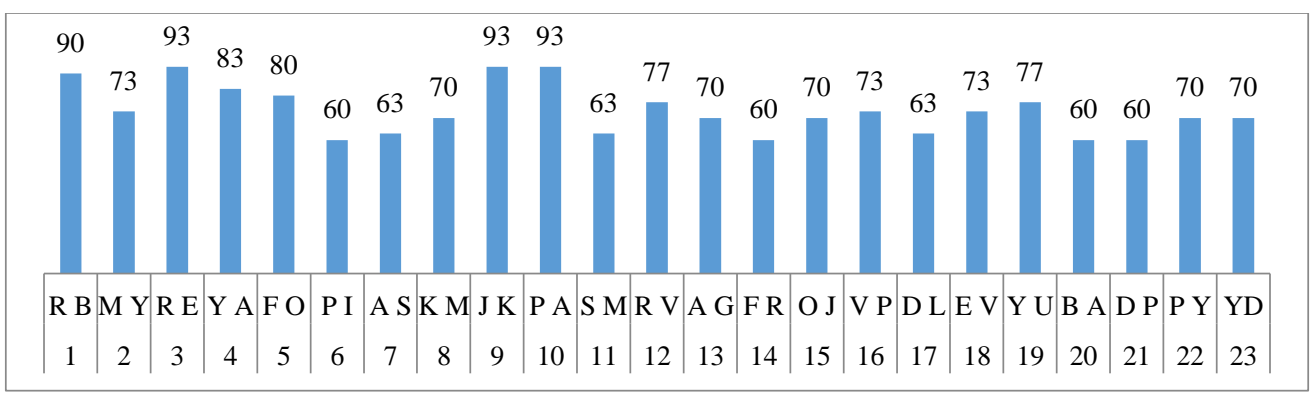

Fig. 3 Students' Score of Participation in English Speaking in Cycle1 Done by Rater 1 and Rater 2

Besides, their low confidence and independence might influence how they did the class presentation. It can be recognized that the use of the strategy and the teaching approach was still new for the students. It can be compared with the note which was noticed by the observer to the researcher to prepare and improve their confidence. Therefore, the researcher prepared the next plan for the second cycle to improve the students' confidence in doing the class presentation so that it influenced them to talk more and enabled them to improve the students' participation in English speaking because the total number of words delivered is also improved.

Cycle 2

The data presented in this study were achieved from the implementation of classroom action research which covers the students' participation in applying the strategy in the first meeting and the second meeting, and students' participation within words in English speaking, students' score of participation in English speaking, and students' responses toward the implementation of Circle Talk through Natural Approach in English speaking.

Students' Participation in Applying the Strategy in Cycle 2

The percentage of the students' participation in applying the strategy in the first meeting (Pre Task and Cycle Task) was $92 \%$ and it was Very Good in the interpretation. Then, $94 \%$ in the second meeting (Language Focus) of Cycle 2 is $94 \%$. It was very good in interpretation.

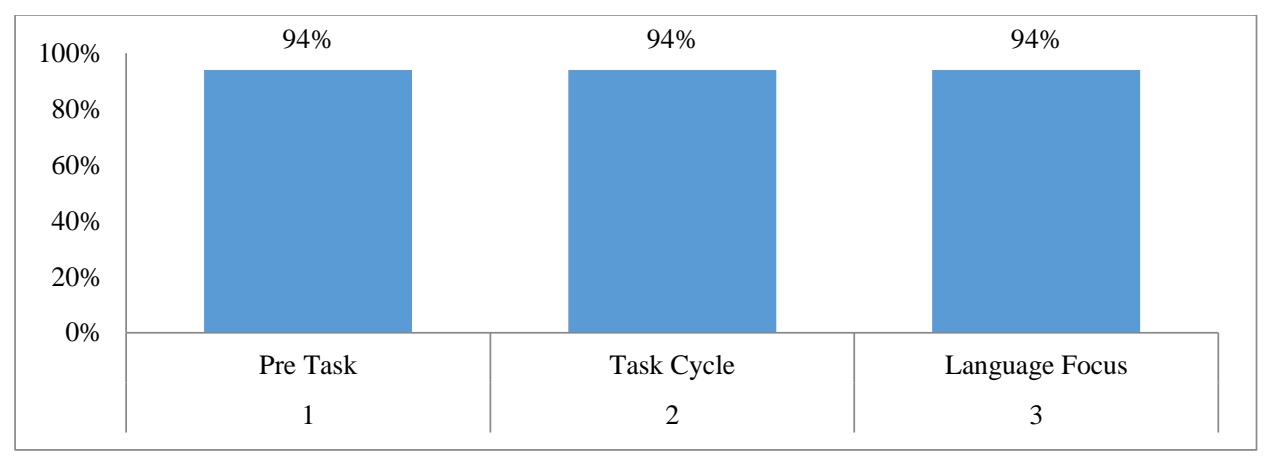

Fig. 4 Students' Participation in Applying the Strategy in Cycle 2

Students' Participation within Words in English Speaking

Based on the video recorded in Language Focus, the researcher (rater 1) and the observer (rater 2) watched, observed the process then took a note and wrote the words which were delivered by students individually. The focus of writing the words was for counting the total number of words per message as their participation in English speaking. The finding was used by the researcher to see the quantity of the students' participation through the total number of words per message delivered. 


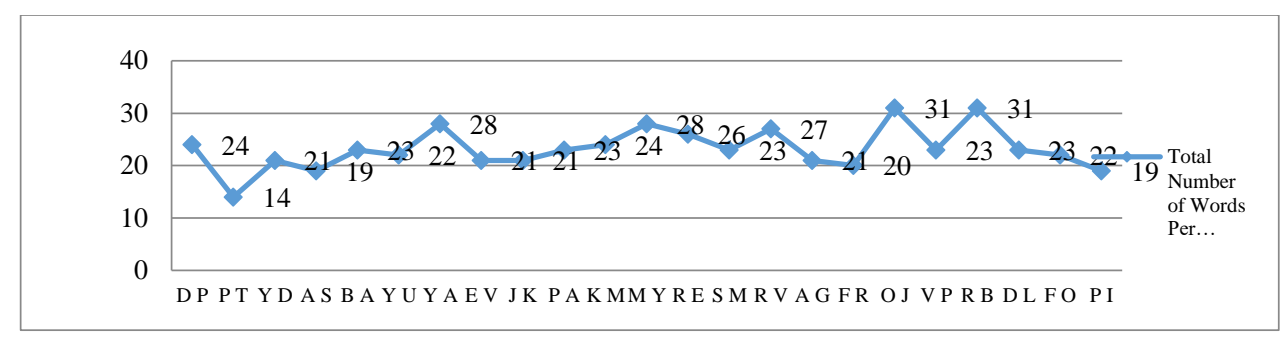

Fig. 5 Students' Participation within Words in Cycle 2

\section{Students' Score of Participation in English Speaking}

The students' final score was achieved from the scoring rubric. The scoring rubric used in measuring the finding was the integration of the total number of words per message delivered by students which was scaled in 1 for ( 1 to 20 words), 2 for ( 21 to 40 words), 3 for ( 41 to 60 words), 4 for (61 to 80 words), and 5 for ( 81 to 100 words) and also the converted speaking rubric in five proper criteria in the frame of Natural Approach.

The conversion of scoring rubric was adapted from the scoring rubric made by Brown (2004, $\mathrm{p}$. 172). They are Task, Pronunciation, Fluency, Comprehension, and Vocabulary. The scoring rubric was adapted by the researcher to meet the standardization objectives of the research finding in the frame of Natural Approach. The data then scored by using scoring rubric done by the two raters. The students' final score the score achieved from rater 1 combined with the score got from rater 2 . It was done to avoid subjectivity in scoring the students' speaking outcome.

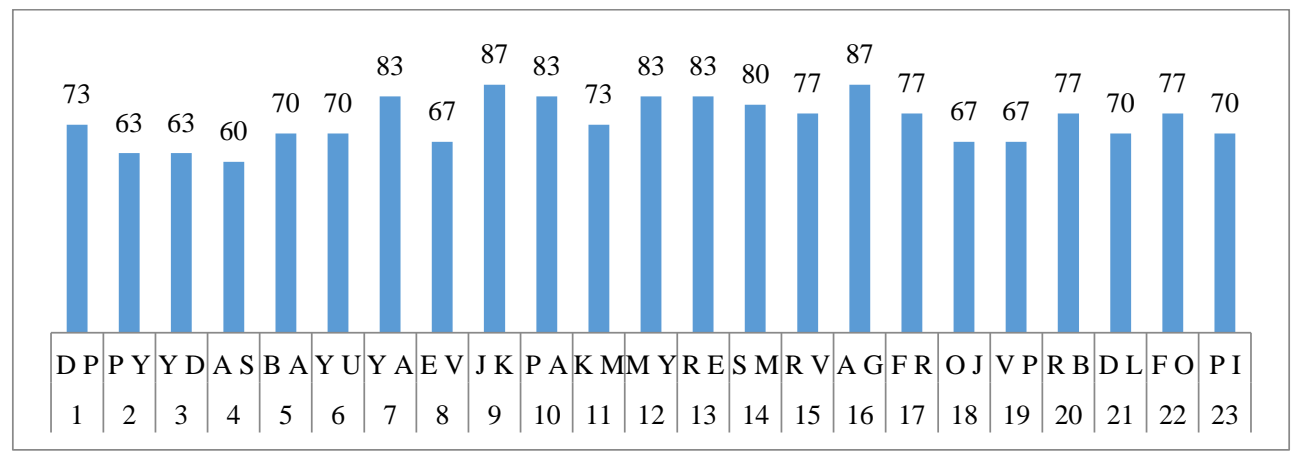

Fig. 6 Students' Score of Participation in English Speaking

\section{Discussion}

The findings of this present study show that the implementation of Circle Talk in Natural Approach to improve students' participation in English speaking can improve the students' participation in English speaking. In the implementation of Circle Talk in Natural Approach to assist and to guide the students to a natural speaking process through the interaction among students facilitates the students to get involved and to imitate the some other friends that have better-quality in English speaking mutually.

The use of Circle Talk and Natural Approach for the teaching learning activities have given positive effects to influence the students' motivation and independence because the language teaching taught based on the students' need without losing the element of fun in learning, comfort and eager during the learning process. Then again, they experienced a cooperative activity in which they could share ideas with friends through the interaction in Circle Talk. Cooperative learning is a particularly useful strategy for promoting, increasing and upgrading the amount of student-initiated talk in the classroom. Thus, the teacher as the researcher thinks that Circle Talk is an authentic teaching strategy that can present cooperative learning in which promote, improve, and upgrade the amount of students-initiated talk in the classroom. According to Cooper (2011), 'a teacher is a person charged with the responsibility of helping others to learn and to behave in new and different ways. 
Therefore, as a practitioner who continually evaluates the effects of his choices and actions on students in the learning community and who actively seeks out opportunities to grow professionally, the researcher thinks that it is very important to use the finding to become the main resource to do the evaluation. It is considered to do so by the researcher because the finding is the final information which is used to start discussing the finding he has. In conclusion, the finding is the whole authentic information in which the researcher used to be discussion.

In relation to the progress of the students' attitude towards English speaking activities, Natural Approach gives a very basic understanding to students to use Natural Approach as the approach in guiding them to be active learners in speaking. Besides, the use of Natural Approach in studying English speaking gives its own characteristics to students that being confidence in speaking as the product of student active is more important than focusing on grammar as the English language structure.

The implementation of the strategy to reach the Language Focus gives the students a chance to build up their confidence to practice speaking individually when they did the presentation to the class. In conclusion, the integration of Circle Talk and Natural Approach in the teaching speaking as its modification and understanding give the new learning atmosphere to students therefore they change the students' attitude into positive thinking that learning English speaking is pleasurable and valuable activity. Then again, Kavaliauskiene and Anusiene as cited in (Marwan, 2014) add that teachers become the key players who can positively or negatively influence the process of students' second or foreign language learning. Thus, the researcher has the belief that the strategy and the approach applied in the research influenced positively to the process of language learning.

\section{CONCLUSION AND SUGGESTION}

\section{Conclusions}

In brief, the finding of this research gives information to other researchers and also the English learners about the link and the effectiveness of using Circle Talk in Natural Approach to improve students' participation in English speaking. Circle Talk is an effective teaching strategy which can be used to improve students' participation in English speaking because Circle Talk encourages the students to independently learn promoting, improving and upgrading the amount of student-initiated talk in the classroom. This teaching strategy creates the atmosphere of learning process in which facilitates students to imitate their friends' English spoken to become their experience and knowledge.

As the teaching approach, Natural Approach supports the use of Circle Talk in encouraging the students to participate and to practice the language teaching. The belief of Natural Approach offers safety to students so that they do not feel really anxious in expressing and exploring comprehensible input through short and simple transactional and interpersonal dialogue when the students do the interaction with the surrounding environment.

The students' participation in English speaking improves through the process of interaction and collaboration among students as they applied the strategy. The finding which was showed in Teacher' Observation Checklist Sheet presents the students' achievement in positive change of behavior. Besides, the implementation of the teaching strategy and also the teaching approach improves the total number of words delivered by the students as the students did the class presentation individually.

\section{Suggestions}

Circle Talk is a technique which is recommended to be used for educators in their teaching speaking because Circle Talk is properly used for many topics and for beginner students, especially in year -8 of SMP. The teachers / researchers who want to integrate the use of Circle Talk as teaching technique to be integrated with Natural Approach as teaching approach are recommended to understand the procedures of Circle Talk and the belief and the objective of Natural Approach with the purpose of making the integration to be relevant. This understanding is very useful for the educators or the teachers to avoid misunderstanding and overlapping procedures and belief in applying the strategy and the teaching approach as conduct conduct them together. The understanding of the steps 
of the strategy and the belief of the Natural Approach guide and support the teachers to maintain the language teaching to be on the track with the intention of keeping the students' attention in the language learning process to presents a comprehensible input for the students.

\section{REFERENCES}

Boyle, J., \& Fisher, S. (2007). Educational Testing: A Competence Based Approach. Malden: Blackwell Publishing.

Brown, H. D. (2004). Language Assessment: Principles and Classroom Practices. New York: Pearson Education.

Burns, A. (1999). Collaborative Action Research for English Language Teacher. Cambridge: Cambridge University Press.

Butcher, C., Davies, C., \& Highton, M. (2006). Designing Learning: From Module Outline to Effective Teaching. Oxon: Routledge.

Cooper, J. M. (2011). The Effective Teacher. In J. M. Cooper, Classroom Teaching Skills (hal. 385). Belmont: Wadsworth Cengage Learning.

Creswell, J. W. (2012). Educational Research: Planning, Conducting and Evaluating Quantitative and Qualitative Rasearch. Boston: Pearson Education, Inc .

Hatch, J. A. (2002). Doing Qualitative Research in Educational Settings. New York: State University of New York Press.

Maley, A., \& Duff, A. (2005). Drama Technique: A Resource Book of Communication Activities for Language Teachers . Cambridge: Cambridge University Press.

Marwan, A. (2014). Teachers' Use of Classroom Language: Some Findings from a BC Training Course. Research Journal of English Language and Litarature (RJELAL) , 221-233.

Mishan, F. (2005). Designing Authenticity into Language Learning Materials. Bristol: Intellect.

Norland, D. L., \& Said, T. P. (2006). A Kaleidoscope of Models and Strategies for Teaching English to Speakers of Other Languages. London: Teacher Ideas Press.

Prinsen, F., Terwel, J., Volman, M., \& Fakkert, M. (2008). Feedback and Reflection to Promote Student Participation. In R. M. Gillies, A. F. Ashman, \& J. Terwel, The Teacher's Role in Implementing Cooperative Learning in The Classroom (hal. 278). New York: Springer.

Rees, F. (2005). The Facilitator Excellence Handbook. San Francisco: Pfeiffer.

Thornbury, S., \& Slade, D. (2007). Conversation: From Description to Pedagogy. Cambridge: Cambridge University Press.

Uba, R. C. (2002). The Natural Approach: An Overview. Rory Cordeiro E Silva, 17.

Winters, A. (n.d.) Using Talking Circles in the Classroom. Heartland Community College, 1. 